

\title{
A INDÚSTRIA TÊXTIL NO BRASIL: UMA ANÁLISE DA IMPORTÂNCIA DA COMPETITIVIDADE FRENTE AO CONTEXTO MUNDIAL
}

\author{
THE TEXTILE INDUSTRY IN BRAZIL: AN ANALYSIS OF THE IMPORTANCE OF \\ COMPETITIVENESS IN THE GLOBAL CONTEXT
}

\footnotetext{
iD André Marques Cavalcanti ${ }^{1}$

iD Gilson Ferreira dos Santos²
}

${ }^{1}$ Doutor em Engenharia Elétrica

Universidade Federal de Pernambuco - UFPE.

Recife, Pernambuco - Brasils.

andre.mcavalcanti@ufpe.br

2 Mestre em Propriedade Intelectual e Transferência de Tecnologia

Instituto Federal de Pernambuco, Campus Pesqueira IFPE.

Pesqueira, Pernambuco - Brasil.

gilson314@gmail.com

Recebido em: 27 jul. 2020

Aprovado em: 06 nov. 2020
Resumo: O Brasil é a 5a maior indústria têxtil e o 4 o no segmento de vestuário no mundo. No entanto, a sua participação no mercado têxtil mundial, é de apenas $0,3 \%$ em volume de negócios observando-se um baixo ganho da capacidade competitiva. Considerando a sua importância para a economia do Brasil este artigo busca analisar a competitividade da cadeia têxtil brasileira considerando os atributos da inovação, construção e promoção de marcas, flexibilidade, produção com padrão de alta qualidade. Nesse contexto, realizam-se análises do atributo inovação a partir de prospecção em bases patentarias mundiais, posicionamento das marcas brasileiras e iniciativas de aumento da produção de insumos como a matéria prima e equipamentos com vistas a identificar a posição competitiva da indústria têxtil brasileira, determinar os principais players em equipamentos, exportações e em desenvolvimento tecnológico do setor têxtil. Dessa forma, estabelece-se quais vantagens competitivas da indústria brasileira que devem ser desenvolvidas com base neste cenário.

Palavras-chave: Competitividade. Indústria têxtil. Inovação tecnológica.

Abstract: Brazil is the 5th largest textile industry and the 4th in the clothing segment in the world. However, its share in the global textile market is only $0.3 \%$ in turnover, with a low gain in competitive capacity. Considering its importance for the economy of Brazil, this article seeks to analyze the competitiveness of the Brazilian textile chain considering the attributes of innovation, construction and promotion of brands, flexibility, production with high quality standards. In this context, analyzes of the innovation attribute are carried out based on prospecting on a worldwide patent basis, positioning of Brazilian brands and initiatives to increase the production of inputs such as raw material and equipment in order to identify the competitive position of the Brazilian textile industry, identifying the main players in equipment, exports and technological development in the textile sector. Thus, it is established which competitive advantages of the Brazilian industry should be developed based on this scenario.

Keywords: Competitiveness. Textile industry. Technologic innovation. 


\section{Introdução}

O Brasil é, atualmente, a $5^{\mathrm{a}}$ maior indústria têxtil do mundo e a 4으 no segmento de vestuário, cuja produção média, em toneladas, é da ordem de 1,3 milhões de têxteis e 6,71 milhões de vestuário (FIEG, 2018). Ainda, é autossuficiente em produção de algodão e é a maior cadeia têxtil completa do ocidente, que produz desde a fibra até o varejo, e pode se tornar exportador mundial de fibras sintéticas com a descoberta do pré-sal (ABIT, 2018). Conforme dados informados pela Associação Brasileira da Indústria Têxtil e de Confecção (ABIT), o Brasil é “o 2oo maior empregador da indústria de transformação, perdendo apenas para alimentos e bebidas", o que demonstra a relevância desse setor para a economia nacional, por demandar o uso intensivo de mão de obra, o que gera rendas e empregos.

Em 2018, a produção de manufaturas têxteis brasileiras alcançou 2 milhões de toneladas, o que representa um faturamento da ordem de US\$ 50,3 bilhões, com estimativas de que essa produção passe dos 2,07 milhões de toneladas em 2019, que indica um faturamento da ordem de US\$ 53,8 bilhões (Prado, 2018). Nesse sentido, pode-se dizer que o Brasil tem uma produção volumosa, tanto para o consumo próprio quanto para a exportação, muito embora o seu maior consumidor seja o mercado interno. Na contramão da sua competitividade, está a forte oscilação cambial e o valor do custo no Brasil, refletido nos custos da mão de obra, nas relações trabalhistas desfavoráveis e nas políticas de inovação tecnológicas deficitárias, além das altas taxas tributárias, o que faz com que países como China e a Índia ocupem a primeira e a segunda posição do ranking mundial da indústria têxtil, sobretudo a China, que produz aproximadamente $50.2 \%$ de têxteis e $47,2 \%$ de vestuário (ABIT, 2015), se tornem um grande desafio a ser enfrentado pela indústria têxtil brasileira. Identificando-se assim, a necessidade de obter ganhos de capacidade competitiva no mercado internacional.

É possível observar que, a partir dos anos 90, um dos impactos causados pela abertura comercial do Brasil foi a perda de competitividade dessa cadeia, sobretudo em relação aos produtores asiáticos (ABIT, 2015). Assim, uma vez que o setor têxtil tem grande importância econômica, em especial no tocante à empregabilidade. Dessa forma, compreender as possibilidades de ganhos de competitividade a partir do conhecimento do cenário mundial atual. Para o aumento desses ganhos, é preciso visualizar quais as estratégias utilizadas atualmente pelo Brasil e o seu contexto, através dos indicadores de competitividade, para que se possa definir as melhores estratégias, a partir da análise do posicionamento dos grandes players internacionais, no caso países.

Dessa forma, o presente artigo inicia-se com uma abordagem a respeito da competitividade e suas características, a partir de análises baseadas em prospeção tecnológica identificam-se os principais players em maquinas, equipamentos e tecidos com novas aplicações e atributos. Buscando-se compreender o estado da arte a partir da prospecção tecnológica, com a observação dos países maiores depositantes de patentes e desenvolvedores de tecnologias no segmento têxtil e de vestuário, nos 
últimos 10 anos, e apresenta-se uma análise e discussão dos dados obtidos e considerações sobre a posicionamento da indústria têxtil brasileira na perspectiva de ganhos da competitividade e vantagem competitiva.

\section{Referencial Teórico}

\subsection{Competitividade e a vantagem competitiva}

As empresas para obterem um posicionamento no mercado estabelecem estratégias que conduzem a um posicionamento competitivo. De acordo com Kožená \& Chládek (2012) o posicionamento é obtido pela medição da competitividade e vantagem competitiva onde se percebe progresso. Em consonância com os esforços para alcançar mais objetivos e proporcionar uma governança corporativa melhor e mais responsável, ainda são elaborados novos métodos e procedimentos. A tendência atual é a aplicação de uma ampla gama de indicadores de várias áreas da empresa que são objeto de ambos os métodos quantitativos (usados para escala numérica mensuração) e os métodos qualitativos (usados para mensuração da avaliação verbal) ou uma combinação de ambos métodos (Donnelly et al., 2006; Hakes, 2007; Watson, Gallagher \& Armstrong, 2005).

Raska, 2007 acrescenta ainda que a competitividade de uma empresa é caracterizada como uma empresa que sabe como competir com sucesso com seus concorrentes nos negócios a longo prazo. Considera que para se medir o desempenho dos negócios não é apenas a quantidade de lucro alcançada, mas também, especificamente, o nível de competividade estabelecido pelos seguintes atributos: inovação, construção e promoção de marcas, flexibilidade, produção com padrão de alta qualidade. Seguindo esse contexto, a inovação está entre os principais fatores de competitividade de uma organização (Lau, 2015).

A Inovação começa a ser considerado como termo-chave para a habilidade administrativa, principalmente na perspectiva da eficácia e do comportamento gerencial das empresas (Kislingerova, 2008). O gerenciamento da inovação eficaz está associada ao processo de tomada de decisões entretanto, respeitando as regras (coerência, complexidade, pontualidade e consistência) que têm uma influência no curso bem-sucedido de inovar (Dytrt \& Striteska, 2009). Associadas a criação inovadoras regulares, uma empresa garante um alto nível de competitividade, pois isso permite que ela reaja com flexibilidade as mudanças dinâmicas tanto na economia quanto no ambiente competitivo (Raska, 2007).

A Construção e promoção de marcas registradas: é fator para a competitividade de uma organização a construção e promoção de marcas (Buil, Catalan \& Martinez, 2015). O Dictionary of Business and Management Kurian (2013) define uma marca comercial como "um nome, sinal ou símbolo que serve para identificar um produto ou serviço de um vendedor específico e que distingue esses produtos ou serviços da competição" (Pallister, 2006). Segundo Keller (2007), considera que uma 
marca comercial é um tipo de produto isso adiciona outra dimensão para distinguir a marca registrada de outros produtos criados para atender às mesmas demandas. Hoje, uma marca expressa a qualidade ou até a posição social da pessoa que a usa. Kotler (2007) descreve as formas de promoção em seu livro Modern marketing. Ou seja, a promoção acontece tanto de forma indireta a um grupo-alvo de clientes em potencial com a ajuda de vários eventos promocionais ou de forma direta, onde a promoção direcionada é usada em um evento para um específico cliente.

A Flexibilidade: o nível de competitividade de uma empresa também depende da flexibilidade (Dirbella, Craigb \& Neubaumc, 2014). O termo flexibilidade está intimamente relacionado à inovação (como descrito acima), porque reflete um nível de prontidão e flexibilidade para reagir às mudanças que realmente ocorreram. Somente uma empresa capaz de reagir rapidamente e efetivamente para novas demandas tem chance de ser competitivo (Koubek, 2011).

A Produção de alta qualidade: A qualidade da produção é outro fator significativo na rivalidade competitiva (Subramain, Gunasekaran, Yu, Cheng \& Ning, 2014). Isso ocorre principalmente quando a oferta de produtos excede a demanda no mercado. Estreitamente ligado a qualidade e produtividade, isso é, como os fatores de produção de trabalho e capital são usados em uma empresa. A verificação da qualidade também está ligada à garantia da qualidade da produção (Veber, 2007).

Retomando ainda o conceito da competitividade Haguenauer (1989) discute a competitividade dividida em dois grupos. O primeiro grupo usa produtividade e coeficientes técnicos como índice, enquanto o segundo é aquele que se expressa a partir de indicadores de parcela de mercado, que garante privilégios ao desempenho no tocante à penetração nos mercados e no número de vendas, o que mensura a sua expansão. Ainda, Cohen e Zysman (1987) definem a competitividade como o grau em que uma nação pode, em condições de mercado livre e justo, produzir bens e serviços que passem no teste dos mercados internacionais, que fazem com que a renda real de seus cidadãos seja expandida simultaneamente. Dessa forma, observa-se que essa abordagem se apresenta de uma maneira bem diferente da tradicional. Busca associar a necessidade da competitividade com um objeto fim específico, e deixa de ser por si só o propósito final.

Sobre os indicadores, apesar de assumirem grande importância no entendimento de uma posição atual de uma determinada indústria, estes não proporcionam segurança de durabilidade, perspectiva de longo prazo. Logo, analisar somente os indicadores não traz nitidez quanto à trajetória das empresas do setor em questão. Assim, para ser possível observar os fatores condicionantes da competitividade, é preciso estabelecer uma sistemática, que segundo Coutinho e Ferraz (1995), acontece a partir do estabelecimento do foco nos fatores indispensáveis para a indústria por completo. Dessa forma, é estabelecido o comportamento característico de agentes do setor e o seu foco empresarial, representado por estratégias definidas por investimentos feitos dentro do campo da sua indústria que se revertem em maior produtividade. Ainda, para obter um resultado satisfatório, é 
necessário um posicionamento estratégico voltado para competitividade, a fim de permitir que a empresa cresça no mercado (Coutinho \& Ferraz, 1995).

Porter (1989), reforça que quando uma empresa estabelece o valor do seu produto para seu cliente a vantagem competitiva surge. Nesse caso, o valor é o que o cliente está disposto a pagar e essa disposição pode acontecer a partir de três fatores: se a oferta for de preços mais baixos do que o da concorrência, se os benefícios forem equivalentes ou no caso de um valor acima, e se os benefícios forem diferenciados e compensem um investimento mais alto. Logo, observa-se que o foco no consumidor é de grande importância na questão da percepção da e criação de produto competitivo, como também pode ser um fator condicionante no resultado das vendas. Dessa forma, percebe-se a necessidade de identificar como é percebida a relação custo/benefício na percepção do consumidor, para o qual o produto se destina, para que ocorra o entendimento real da vantagem competitiva.

\subsection{Inovação da indústria têxtil}

Em meio a tantas técnicas aplicadas com o intuito de manter-se competitivo no mercado, no setor têxtil, uma das mais importantes é a inovação. Nessa ótica, essa palavra tem seu conceito renovado quase instantaneamente, quando se analisa sobre a tecnologia voltada para indústria têxtil. Novos elementos que facilitam inovar surgem com o uso da computação e a criação de materiais sustentáveis mostram-se, a cada dia, mais presentes no mundo da moda, em objetos, nos esportes e nos uniformes, e tem-se todos esses elementos voltados para os equipamentos e tecidos no setor têxtil em geral (Tidd, Bessant e Pavitt, 2008).

Nos tecidos, a evolução tecnológica proporciona funcionalidades relevantes que podem ser um diferencial crucial para o sucesso do negócio. Para Tidd, Bessant e Pavitt (2008) inovar é uma condição necessária para criar vantagem competitiva. Assim, a inovação é aplicada na forma em que a produção têxtil provoca mudanças, no tocante ao usufruto dos benefícios desses produtos, o que facilita o dia a dia das pessoas e melhora a capacidade produtiva das indústrias. Nesse sentido, observa-se, no setor têxtil, a introdução no processo industrial de robôs chamados de Sewbots, os quais auxiliam em todo o processo de confecção, na colocação das etiquetas, até mesmo no controle de produção e estoque, o que torna as empresas mais produtivas.

Outra inovação já em uso no setor têxtil, e nesse caso voltada para economia e sustentabilidade, é a impressão 3D. Essa inovação, visa diminuir o desperdício dos tecidos no processo de confecção, como também é capaz de aperfeiçoar as técnicas de customização bem como um melhor aproveitamento do tempo investido na produção (CARLOTA, 2018). Com essa tecnologia na fabricação têxtil, é grande a diminuição no descarte de resíduos de materiais, bem como a redução de tempo para 
customização de uma peça, uma vez que é na criação que se aplicam os ajustes, e as implementações às modelagens, antes da confecção.

\subsection{Inovação na Indústria de vestuário}

Em uma concepção que une design, arte e ciência, novas peças são elaboradas, em busca da perfeição no corte e no acabamento, e da valorização do caráter sustentável. Cassiolato (2000) afirma que a inovação é um processo que as empresas dominam e implementam o design e a produção de bens e serviços que sejam novos. A partir disso, as inovações voltam-se para os métodos produtivos, e na variação e melhoria do produto. Assim, as empresas direcionam seus investimentos nos conceitos de moda e design, bem como na implementação de novas estratégias. A tecnologia tem promovido um avanço considerável no setor de criação, corte e costura, por meio dos programas de computadores como: CAD (Computer Aided Design - Desenho assistido por computador), CAM (Computer Aided Manufactoring - Manufatura assistida por computador) e CIM (Computer Integrated Manufacturing Manufatura integrada por computador), como também no aprimoramento dos equipamentos, máquinas e elementos de produção (COSTA; ROCHA, 2009). De acordo com Costa e Rocha (2009), esses programas permitem projetar uma peça de vestuário em duas e até em três dimensões no computador e transmitir essa criação através de interfaces de comunicação entre o computador e um sistema de fabricação, que executa a produção automaticamente.

\subsection{Prospecção tecnológica e sua importância para o posicionamento no mercado nacional e internacional}

A prospecção tecnológica, para Amparo, Ribeiro e Guarieiro (2012), possui um papel decisivo capaz de reduzir incertezas e orientar os processos de tomada de decisão estratégica quanto ao desenvolvimento de uma inovação tecnológica. Nos últimos anos, as mudanças tecnológicas mostram a necessidade e a importância no uso das informações corretas para facilitar e orientar o futuro, as quais são oriundas de estudos prospectivos.

Coelho et al. (2005), Geldes et al. (2017), consideram a prospecção como um método para identificar oportunidades e necessidades mais importantes para a pesquisa e desenvolvimento (P\&D). Nesse contexto, entende-se que a prospecção tecnológica tem um papel de relevante importância na empresa perante o mercado, pois ela é capaz de nortear o processo de tomada de decisão, o que facilita o desenvolvimento de estratégias de inovação em uma empresa ou indústria. Estudos voltados para a prospecção tecnológica, ainda fornecem subsídios no tocante aos desenvolvimentos tecnológicos e científicos, que facilitam a visualização do mercado de maneira ampla, a partir da análise mais precisa dos concorrentes e, consequentemente, facilita também a tomada de decisão. 
Para se fazer a prospecção tecnológica através de documentos Patentários podem ser usados sistemas online disponibilizados na internet, como por exemplo, Orbit Intelligence (https://www.orbit.com), Lens (https://www.lens.org), Google Patents (https://patents.google.com/), Espacenet (http://worldwide.espacenet.com/), Patentscope (http://patentscope.wipo.int/) e a base do Instituto Nacional de propriedade Intelectual (INPI) entre outras.

Levando-se em consideração todos aspectos aqui abordados é possível perceber que quando não se capaz de observar o cenário a partir dos atributos dos ganhos em capacidade competitiva não é possível ainda reconhecer os principais players que podem já estar presentes no mercado e sendo assim uma ameaça muito próxima.

\section{Metodologia}

Considerando as hipóteses de que uma empresa não poderá ser competitiva se não for capaz de identificar os seus concorrentes e para ser inovadora no setor da indústria que atua necessitará utilizar bem as técnicas de prospecção tecnológica. Dessa forma na metodologia utilizada nessa pesquisa por seus objetivos, trata-se de pesquisa exploratória, por considerar que a área necessita de pesquisa contínua motivada pela dinâmica da sociedade nas suas relações, além da escassez de produção científica que contemple as estratégias sobre a alta competitividade no mercado têxtil na sua dinâmica, o que torna o tema sempre inovador. O caráter exploratório permite uma maior aproximação dos sujeitos com o experimento na construção das estratégias da alta competitividade. Assim, esta pesquisa tem como objetivo proporcionar uma melhor compreensão de problema, com vistas a tornálo mais explícito (Gil, 2002, p. 41). Dessa forma, a pesquisa foi desenvolvida em quatro etapas.

A etapa 1 se refere a apresentação do panorama do mercado da indústria têxtil mundial no período de 2010 a 2017 a partir de dados obtidos de IEMI/Fiber Organon (2018). Esse recorte é utilizado pela falta de dados referentes ao ano de 2018 e 2019. São apresentados os dados de mercado de fibras naturais e químicas, têxtil e vestuário, exportação de têxtil e vestuário, exportação de têxtil e vestuário indicando os principais exportadores e importadores.

Na execução da etapa 2 contempla a busca de informações na base de dados de pedidos de patentes do setor têxtil e artigos acadêmicos associados ao desenvolvimento de patentes. Para isso são utilizados dois sites de busca de patentes The Lens (Lens.Org, 2020), que é um recurso on-line de pesquisa de patentes da Cambia, uma organização internacional sem fins lucrativos, independente e dedicada à democratização da inovação, que oferta busca livre em 121,4 milhões de registros de patentes, 105 Jurisdições e 66,3 milhões de famílias de patentes. Como também se usou o site da WIPO (www.wipo.int), que fornece dados estatísticos complementares de patentes por países. Para a busca de informações, utiliza-se o período de interesse dos pedidos de depósitos e publicação de patentes 
entre 25/06/2010 a 25/06/2020, buscando-se os pedidos de patente de invenção, o modelo de utilidade e o certificado de adição depositados em todas as classes relativas à seção D, e classe D01 a D06, que são relacionadas à área têxtil, da Classificação Internacional de Patentes (IPC). A partir desses dados, realizar-se a análise do tema buscando-se extrair as principais características da indústria têxtil brasileira e sua capacidade competitiva no mercado internacional. A partir desse conjunto de dados é realizada uma análise quantitativa através da compilação em relatórios estatísticos e gráficos referentes ao desenvolvimento de tecnologias para indústria têxtil.

A etapa 3 a partir do referencial teórico sobre competitividade e das informações compiladas na etapa 2 busca-se estabelecer os elementos que caracterizam o posicionamento da indústria têxtil brasileira frente aos concorrentes internacionais.

A etapa 4 realiza-se a análise das informações obtidas e considerações sobre o posicionamento da indústria têxtil brasileira frente ao mercado.

\section{Panorama da cadeia têxtil mundial (etapa 1)}

A indústria têxtil em função da sua cadeia produtiva, apresenta uma forte tendência de crescimento tanto em produção quanto na participação no comércio internacional como um todo. À medida em que a renda per capita da população aumenta, haverá certamente crescimento do consumo de têxteis.

\subsection{Consumo de fibras}

A figura 1 representa a distribuição do consumo mundial de fibras têxteis entre 2010 e 2017. Em 2017 o consumo mundial de fibras têxteis foi de 100,3 milhões de toneladas, sendo 73,9\% de fibras químicas e 26,4 de fibras naturais. Entre 2000 e 2017 ocorreu um aumento de consumo de fibras têxteis da ordem de $67,7 \%$. Nesse mesmo período observa-se que houve praticamente uma estabilização do consumo de fibras naturais. 
Figura 1

Consumo mundial de fibras têxteis (milhões de toneladas) no período de 2010 a 2017

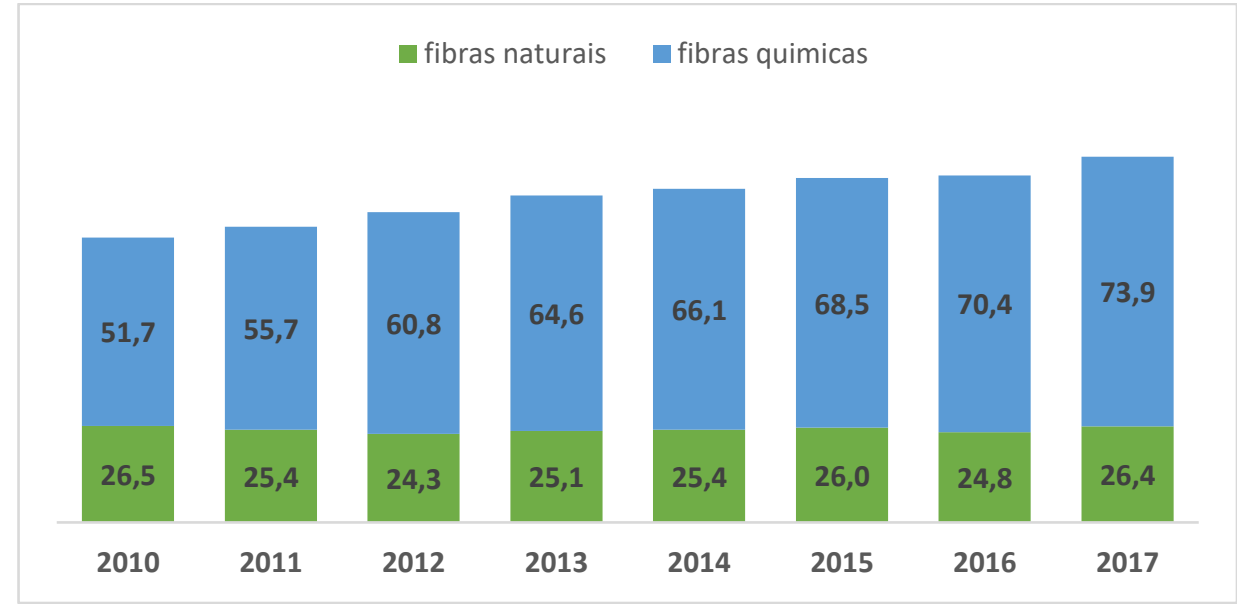

Fonte: IEMI (2018),

\subsection{Mercado mundial de têxteis e vestuários}

A figura 2 representa a movimentação, em bilhões de dólares, das vendas de têxteis e vestuários no mercado internacional entre 1950 e 2017. Fazendo uma análise desse quadro, observa-se que a movimentação de capital no mercado mundial de têxteis e vestuário foi da ordem de US\$ 781,7 bilhões, em 2017, sendo 58\% de vestuário e 48\% de têxteis. Um aumento de 128\% no setor de vestuário contra 109\% no setor de têxteis nesses últimos dezessete anos.

Figura 2

Movimentação de capital em vendas de vestuários e têxteis em US bilhões no período de 1990 a 2017

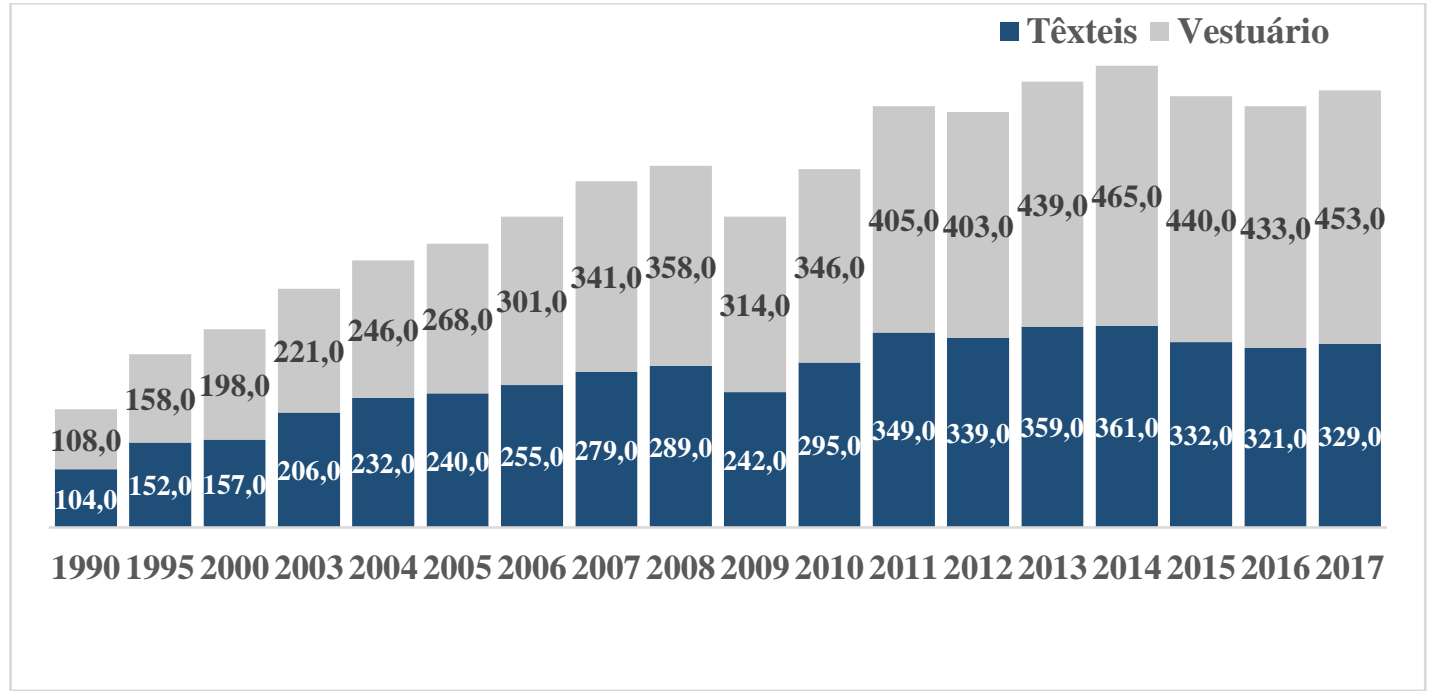

Fonte: IEMI (2018) 


\subsubsection{Exportações de têxteis e vestuários}

IEMI (2018) em seu relatório apresenta o ranking dos principais players exportadores do setor têxtil mundial, destacando a liderança da China, que sozinha detém 33\% do total de têxteis e de vestuário exportados em 2017, seguida por Bangladesh e Alemanha, com 4,6\% cada, Itália e Vietnã com 4,3\% cada. O Brasil ocupa a 41 posição (26a em têxteis e 79a em vestuário), cuja participação total é de apenas $0,3 \%$.

\subsubsection{Principais países importadores}

IEMI (2018) em seu relatório também exibe os países que mais importam produtos têxteis e de vestuário, dando destaque para a liderança dos estados Unidos, que sozinhos são responsáveis por 15,9\% de todas as importações de têxteis mundiais, seguido pela China, com 7,3\% e Vietnã com 4,9\%. Nesse ranking, o Brasil está na 30ª (26ạ em têxteis e 39ạ em vestuários) posição com participação de $0,7 \%$ apenas, o que o caracteriza como um país produtor - consumidor.

\section{Prospecção tecnológica de patentes (etapa 2)}

Através do documento de patente, quer seja de um pedido de patente ou uma patente concedida, se obtém informações tecnológicas relevantes, as quais geralmente não são disponibilizadas na maioria dos livros. Esses documentos proporcionam informações sobre o estado da técnica sobre qualquer tecnologia (INPI, 2012). Para se indexar e recuperar os pedidos de patentes depositados no mundo, utiliza-se a Classificação Internacional de Patentes (IPC), que é dividida em oito seções, com destaque para a seção $\mathrm{D}$ a qual é subdividida em seis classes, de acordo com a natureza tecnológica dos produtos e processos, apresentada no Quadro 1. 
Quadro 1

Classificação internacional de patentes (IPC) e classes da seção D

\begin{tabular}{|l|l|}
\hline Seção & Área \\
\hline A & Necessidades humanas. \\
\hline B & Operações de processamento; transporte. \\
\hline C & Química e metalurgia. \\
\hline D & Têxteis e Papel. \\
\hline E & Construções fixas. \\
\hline F & Engenharia mecânica; iluminação; aquecimento; armas; explosão. \\
\hline G & Física \\
\hline H & Eletricidade \\
\hline Classe D & Descrição \\
\hline D01 & Fibras naturais ou artificiais; fiação \\
\hline D02 & Fios; acabamento mecânico de fios ou cordas; urdidura ou tecedura. \\
\hline D03 & Tecelagem \\
\hline D04 & Entrançamento; fabricação de renda; malharia; passamanaria; não tecidos. \\
\hline D05 & Costuras; bordados; implantação de tufos. \\
\hline D06 & $\begin{array}{l}\text { Tratamento de têxteis ou similares; lavanderia; materiais flexíveis não incluídos em outro } \\
\text { local; }\end{array}$ \\
\hline
\end{tabular}

Fonte: INPI (2020).

\subsection{Análise dos pedidos de patente relativos ao setor têxtil mundial entre 2010 - 2020}

Utiliza-se o The Lens (2020) para realizar a busca de patente relativos ao setor têxtil, dentro da classificação dos grupos D01 a D06, sob a jurisdição do PCT (Tratado de Cooperação em Matéria de Patentes) que engloba 153 países. A busca é realizada limitada aos documentos de patente depositados e publicados, entre 26 de junho de 2010 e 26 de junho de 2020, onde observa-se 537.723 resultados. A figura 3 apresenta a distribuição de países com prioridade para os pedidos de patentes efetuados em cada jurisdição pertencente ao PCT. De acordo com a distribuição dos países para os pedidos de patentes depositados, referentes ao setor têxtil e publicados entre 2010 e 2020, a China lidera com 252.570 (47,50\%), seguido do Japão, com 64.398 (12,11\%), depois Estados Unidos, com 48.250 (9,07\%) e o Brasil, em oitavo lugar com 8.528 (1,60\%).

\subsection{Distribuição das IPCs informadas nos documentos de patentes sob a jurisdição do PCT (2010 - 2020)}

A figura 3 representa a range das 20 classificações IPCs (D01 a D06) mais colocadas do setor têxtil (Classe "D"), encontradas nos documentos de patente prospectados entre 2010 e 2020. Dessa forma, é possível se verificar quais classificações internacionais de patentes são mais frequentes e quais setores da tecnologia são mais efetivos no desenvolvimento do setor têxtil. As subclasses D03D15/00 (22.297), D01F1/10 (16.847), D06F33/02 (13.569), D06F39/08 (11.938), D02G3/04 (11.021), D06F39/00 (10.984) e D06M101/06 (10.089) são as que se destacam mais. Se observa 11 ocorrências da subclasse 
D06 (Tratamento de têxteis ou similares; lavanderia; materiais flexíveis) e 2 da subclasse D01(Fibras naturais ou artificiais; fiação). A classificação D06 e D01 são as de maiores impactos no setor têxtil.

Figura 3

Distribuição das IPCs informadas nas patentes do setor têxtil sob a jurisdição do PCT (2010 -2020)

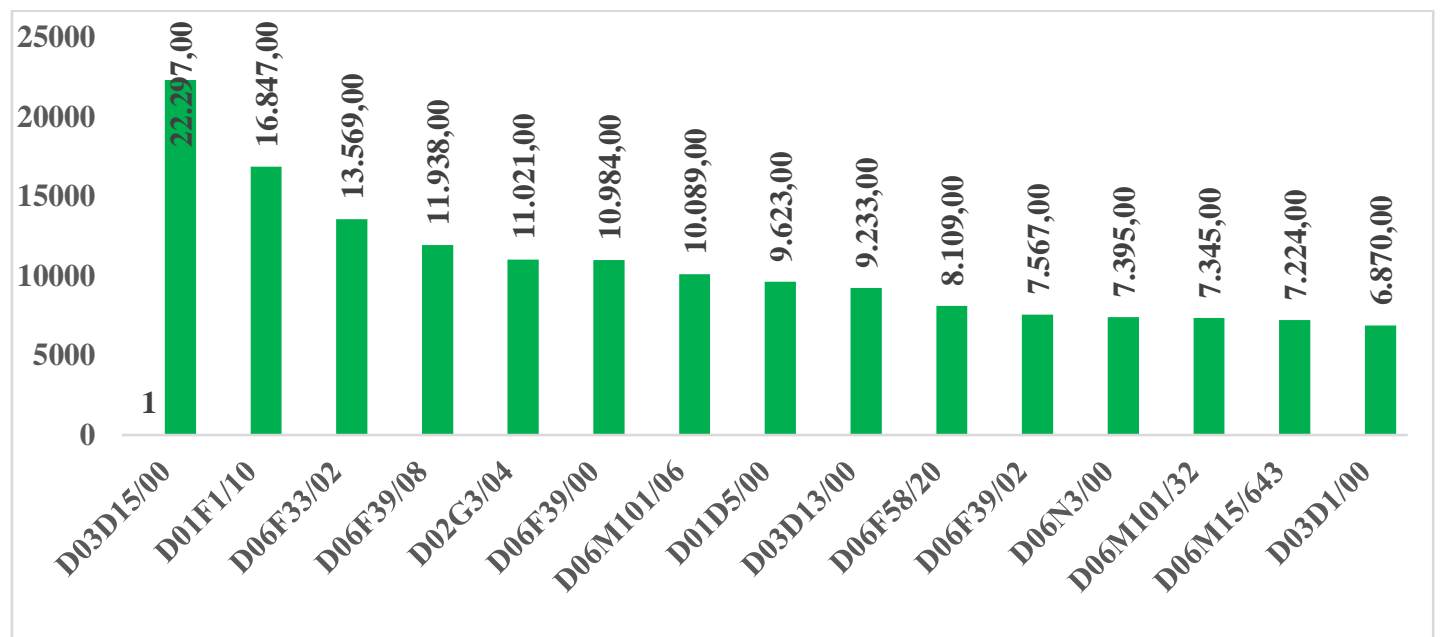

Fonte: The Lens (último acesso 20/07/2020)

\subsection{Distribuição das IPCs informadas nas patentes do setor têxtil no Brasil entre 2010 - 2020}

A figura 4 representa o resultado da prospecção tecnológica de patente relativas ao setor têxtil, dentro da classificação dos grupos D01 a D06, restrita ao Brasil, entre 2010 e 2020. A pesquisa retornou 427 resultados e a distribuição das IPCs destaca as subclasses D04H13/16 (58), D04H1/42 (51), D04H13/00 (47), D01F1/10(46) e D0639/02(35). As subclasses D06 e D01 (Tratamento de têxteis ou similares; lavanderia; materiais flexíveis) e (Fibras naturais ou artificiais; fiação) aparecem como uma das mais bem colocadas, justamente as duas mais significativas do setor têxtil. 
Figura 4

Classificação IPC relativas a patentes prospectadas no Brasil entre 2010 - 2020

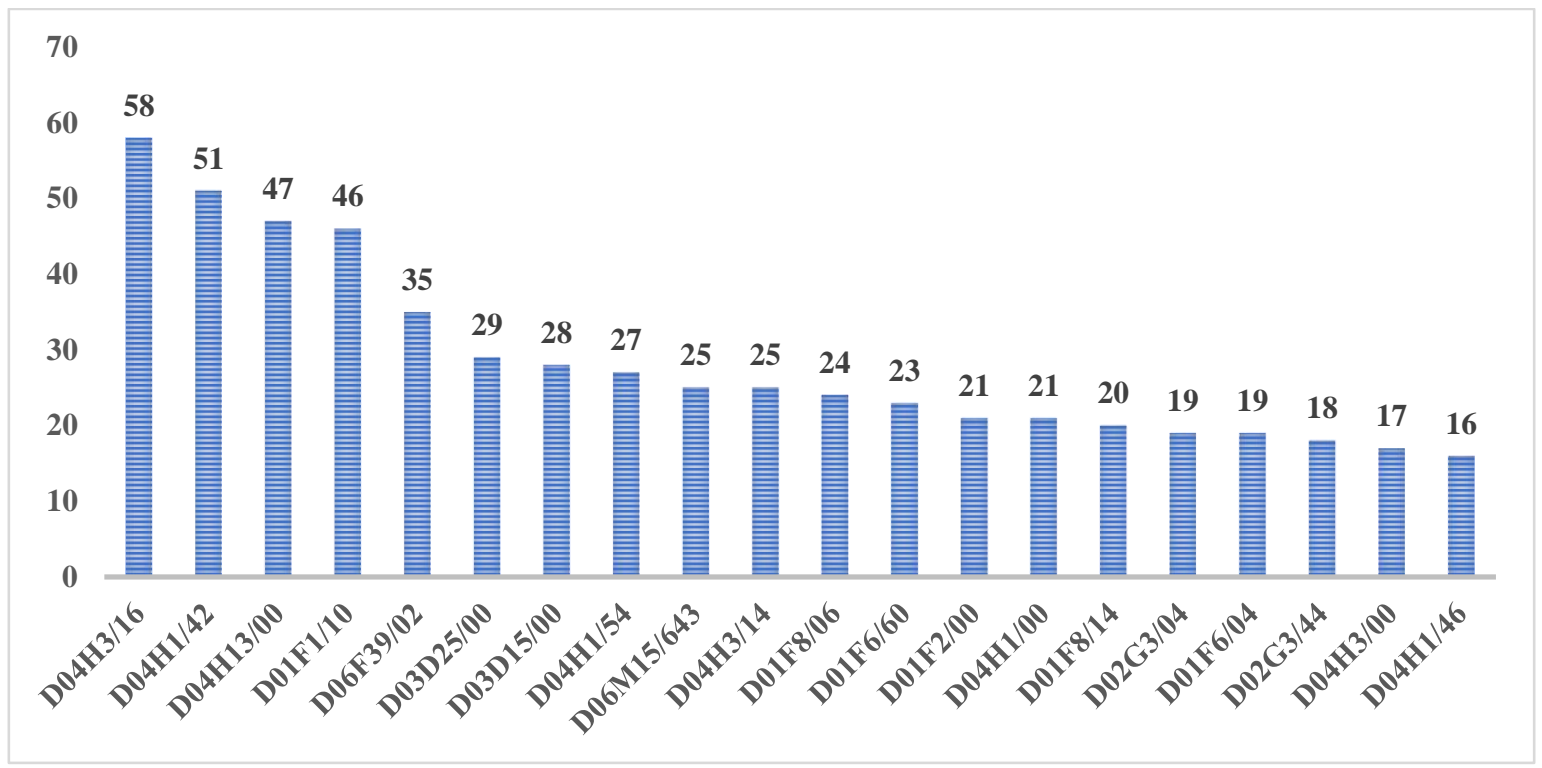

Fonte: The Lens (2020).

5.4 Patentes de residentes e não residentes depositadas no Brasil referentes ao setor têxtil em 2010 2020

A figura 5 mostra o resultado da busca de pedidos de patente, dividido por residente e não residente, na base da Wipo (Organização Mundial de Propriedade Intelectual), em sua seção de estatísticas do Brasil, relativos ao período entre 2009 a 2018, o que retornou 276.459 resultados. Pode ser observado um comportamento praticamente constante nos pedidos de patentes residentes no Brasil entre 2009 e 2018. Já em relação aos pedidos de patente não residentes essa curva é crescente até 2015, e a partir daí chega em 2018 praticamente aos mesmos valores de 2009. 
Figura 5

Pedidos de patentes residentes e não residentes depositados no Brasil (2009 - 2018)

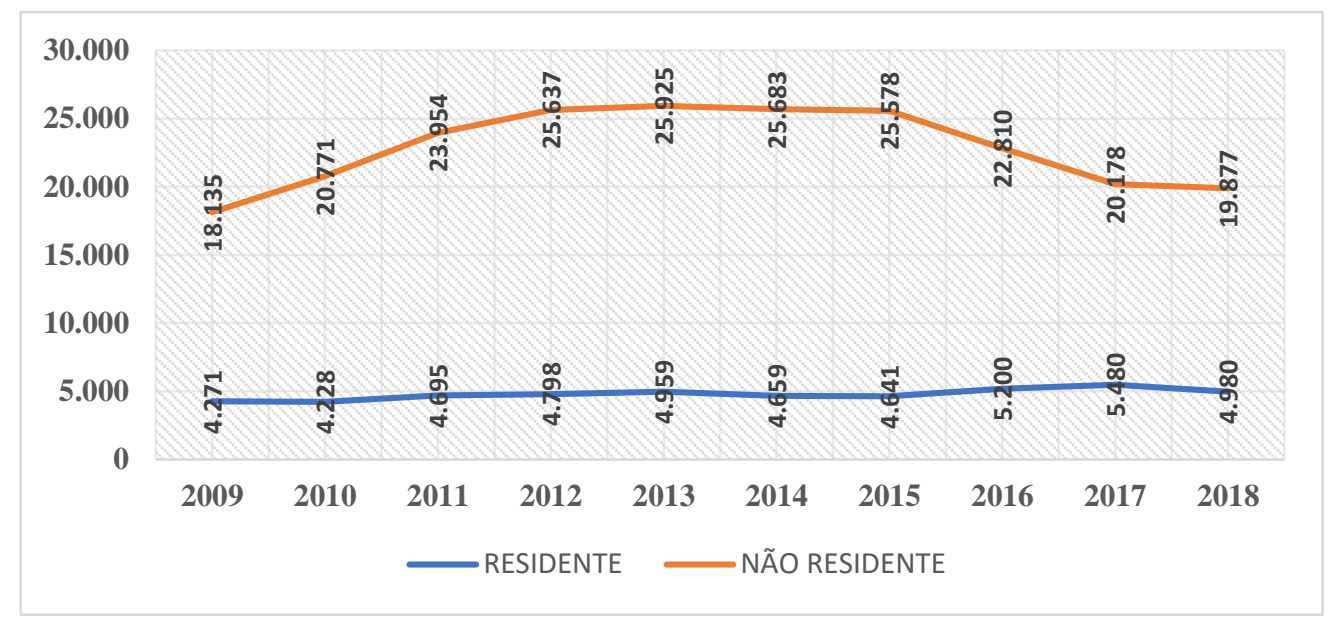

Fonte: WIPO (2020).

\section{Análise da Capacidade Competitiva da Cadeia Têxtil Brasileira (etapa 3)}

Conforme visto na seção 2 a competitividade e vantagem competitiva são estabelecidas através de esforços para alcançar mais objetivos e proporcionar uma governança corporativa melhor e mais responsável. Nessa perspectiva são utilizados vários indicadores que visam avaliar as dimensões Inovação, Construção e Promoção de Marcas, Flexibilidade e Produtos com alto padrão de qualidade.

Observa-se então que a cadeia têxtil brasileira como a mais completa do ocidente, caracterizada por uma produção que vai desde a produção de fibras, por exemplo o algodão, passando pela fiação e o beneficiamento até a ponta final do produto, com um varejo robusto no mercado interno. É um setor com quase 200 anos, tido como referência mundial em design de moda praia, jeanswear e homewear. E ainda o Brasil ocupa, conforme mostra a tabela 1, o $5^{\circ}$ lugar no ranking mundial da indústria têxtil, o que significa $2,4 \%$ da produção mundial de têxteis e o $4^{\circ}$ lugar no ranking mundial da indústria de vestuário, o que representa $2,6 \%$ da produção mundial de vestuário. 
Tabela 1

Participação dos países na produção mundial de têxteis e vestuário

\begin{tabular}{llll}
\multicolumn{1}{c}{ PRODUÇÃO DE TÊXTEIS } & \multicolumn{2}{c}{ PRODUÇÃO DE VESTUÁRIO } \\
CAÍS & \multicolumn{2}{c}{$\%$} & \multicolumn{2}{c}{ PAÍS } \\
China & 50.20 & China & 47.2 \\
Índia & 6.90 & Índia & 7.1 \\
Estados Unidos & 5.30 & Paquistão & 3.1 \\
Paquistão & 3.60 & Brasil & 2.6 \\
Brasil & 2.4 & Turquia & 2.5 \\
Indonésia & 2.4 & Coreia do Sul & 2.1 \\
Taiwan & 2.3 & México & 2.1 \\
Turquia & 1.9 & Itália & 1.9 \\
Coreia do Sul & 1.8 & Malásia & 1.4 \\
Tailândia & 1.1 & Taiwan & 1.4 \\
México & 0.9 & Polônia & 1.4 \\
Bangladesh & 0.8 & Romênia & 1.2 \\
Itália & 0.8 & Indonésia & 1.1 \\
Rússia & 0.7 & Bangladesh & 1 \\
Alemanha & 0.5 & Tailândia & 1 \\
Outros & 18,4 & Outros & 22.7
\end{tabular}

Fonte: FIEG (2018).

Segue-se então a análise de informações sobre a indústria têxtil brasileira que demonstram o seu esforço para obterem vantagem competitiva.

\subsection{Produção de têxteis por segmento (etapa 3)}

A tabela 2 fornece os dados da produção de têxteis da indústria brasileira entre o período de 2013 a 2017, em toneladas. Observando que em 2017 a produção de fibras e filamentos teve um ligeiro incremento de 0,69\%, já os bens manufaturados têxteis apresentaram uma alta em torno de 5,8\%, com destaque para os não tecidos, que tiveram um aumento de $6,1 \%$, seguidos pelos fios, com $3,6 \%$, malhas, com $1,3 \%$ e tecidos com $2,3 \%$. Os confeccionados obtiveram $1 \%$ de incremento na produção, acessórios e meias, 2,3\%, mas os artigos do lar decresceram em 3,9\%. De modo geral, entre 2013 e 2017, os dados demonstram que a produção de manufaturados têxteis recuou $2 \%$ e a de confeccionados $9,7 \%$ em relação ao resultado de 2013. Vale lembrar aqui que 99,7\% dessa produção é dirigida ao mercado brasileiro (interno) e só 0,3\% se destina a exportação (IEMI, 2018). 
Tabela 2

Comparação da Produção de têxteis em volume (tonelada) com balança comercial em dólar americano (US\$ mil) e investimentos em máquinas, equipamentos e processos

\begin{tabular}{|c|c|c|c|c|c|}
\hline & 2013 & 2014 & 2015 & 2016 & 2017 \\
\hline ProducãoTêxil (tol) & $2.051 .436,00$ & 2.092 .222 & $1.839 .325,00$ & 1.901 .103 & 2.011.254,00 \\
\hline ProducãoConfecciomados & $1.853 .478,00$ & 1.854 .353 & 1.713.189,00 & 1.658.659 & $1.674 .509,00$ \\
\hline \multicolumn{6}{|c|}{ Investimento emequipamentos e processo (emmilhões de dolar americamo) } \\
\hline Fibras e Filamentos & 492 & 228 & 70 & 67,9 & 38 \\
\hline Têxtil & $1.124,50$ & 943,4 & 451,4 & 441,2 & 531,6 \\
\hline Confeccionados & 714,8 & 6529 & 348,2 & 344,1 & 415,5 \\
\hline Total de investimento & 2.331,30 & $1.824,40$ & 869,6 & 853,3 & 985 \\
\hline Exportação & 1300,562 & 1535,446 & 1432,148 & 1332,528 & 1473,361 \\
\hline Importação & 260,465 & 291,923 & 209,186 & 223,879 & 282,257 \\
\hline Saldo & 1040,09 & 1243,523 & 1222,962 & 1108,649 & 1191,103 \\
\hline \multicolumn{6}{|l|}{ Filamentos (U\$1000) } \\
\hline Exportação & 53,513 & 61,611 & 64,565 & 59,998 & 61,581 \\
\hline Importação & 852,578 & 918,093 & 668,789 & 634,643 & 753,281 \\
\hline Saldo & $-799,065$ & $-856,483$ & $-604,134$ & $-574,646$ & $-691,699$ \\
\hline \multicolumn{6}{|l|}{ Manufaturas Têxteis } \\
\hline Exportação & 772,295 & 725,234 & 687,646 & 629,784 & 618,425 \\
\hline Importação & 2957,363 & 2993,385 & 2290,706 & 1903,024 & 2240,76 \\
\hline Saldo & $-2185,068$ & $-2268,151$ & $-1603,06$ & $-1273,239$ & $-1622,336$ \\
\hline \multicolumn{6}{|l|}{ Confeccionados } \\
\hline Exportação & 257,212 & 229,091 & 200,176 & 201,483 & 231,516 \\
\hline Importação & 2824,628 & 3049,009 & 2768,196 & 1507,246 & 1892,271 \\
\hline saldo & $-2567,416$ & $-2819,917$ & $-2568,02$ & $-1305,763$ & $-1660,754$ \\
\hline \multicolumn{6}{|l|}{ Total } \\
\hline Exportação & 2383,582 & 2551,382 & 2384,626 & 2223,793 & 2384,883 \\
\hline Importação & 6895,035 & 7252,41 & 5936,878 & 4268,792 & 5168,569 \\
\hline Saldo & $-4511,453$ & $-4701,028$ & $-3552,252$ & $-2044,999$ & $-2783,687$ \\
\hline \multicolumn{6}{|c|}{ Total de manufaturas têxteis e confeccionados } \\
\hline Exportação & 1029,507 & 954,325 & 887,822 & 831,267 & 849,941 \\
\hline Importação & 5781,992 & 6042,394 & 5058,903 & 3410,269 & 4133,031 \\
\hline SaldoFinal & $-4752,484$ & $-5088,068$ & $-4171,08$ & $-2579,002$ & $-3283,09$ \\
\hline
\end{tabular}

\subsection{Saldo da balança comercial da cadeia têxtil e de confecção (etapa 4)}

A tabela 2 fornece dados da balança comercial da indústria têxtil brasileira no período entre 2013 e 2017, e a análise desses dados mostra um aumento do déficit comercial de US\$ 800 milhões entre 2016 e 2017, em relação ao segmento de manufaturas têxteis e produtos confeccionados, e um déficit de US\$ 692 milhões no segmento de filamentos. Já o segmento de fibras foi o único que apresenta um superávit de US\$1,2 bilhões nesse mesmo período. Observa-se que na Figura 1 no consumo mundial das fibras sintéticas um crescimento de $42,9 \%$, enquanto, as fibras naturais não apresentam crescimento significativo ao logo do período avaliado (2010-2017). A partir dessa observação percebe-se uma incerteza quanto ao futuro desse tipo de consumo tendo em vista a estabilização do consumo. 
6.3 Investimentos (máquinas e processos) (etapa 4)

A tabela 2 mostra que o setor é tido como inovador e procura se manter sempre à frente na vanguarda de investimentos em inovação e inserção de novas técnicas e processos. Segundo estimativas feitas pelo IEMI, os investimentos em treinamentos, processos, e aumento da produtividade foi da ordem de R\$ 3,1 bilhões, significando uma alta de $2 \%$ em relação a 2017. Já os investimentos em máquinas e equipamentos em 2017 atingiram a casa dos $\mathrm{R} \$ 2,3$ bilhões, o que representa uma alta de 35,3\% em relação a 2016. Os segmentos da cadeia têxtil que tiveram maiores investimentos em máquinas e equipamentos foram os dos confeccionados, na casa dos $46,8 \%$. Já o segmento de não tecidos apresentou uma queda da ordem de 14,3\%. É relevante observar que apesar desse esforço não são estabelecidos ganhos de competitividade no mercado exterior.

\subsection{Compilação das análises (etapa 4)}

Verifica-se então que existe um esforço das empresas que compõem o parque da indústria têxtil brasileira para atenderem as dimensões da competitividade e da vantagem competitiva. Porém, esse esforço não tem sido conduzido da forma que se atinja um destaque mundial como se verifica a seguir. Do ponto de vista de investimento em Inovação o Brasil fica muito distante dos países líderes no cenário mundial onde se destaca apenas no desenvolvimento da produção de fibras naturais em um mercado que não apresenta crescimento. Em inovação não se percebe um real esforço quando são comparados os números de depósitos de patentes nas bases mundiais associadas a indústria têxtil, pois verifica-se na Análise dos pedidos de patente relativos ao setor têxtil mundial entre 2010 - 2020 na figura 3 que apresenta a distribuição de países com prioridade para os pedidos de patentes efetuados em cada jurisdição pertencente ao PCT. De acordo com a distribuição dos países para os pedidos de patentes depositados, referentes ao setor têxtil e publicados entre 2010 à 2020, a China lidera com 252.570 (47,50\%), e o Brasil, em oitavo lugar com 8.528 (1,60\%). Além disso, verifica-se na base do INPI, figura 5, que o número de depósitos de patentes no Brasil dos residentes não ultrapassa a marca de 5.000 pedidos em média nos últimos 10 anos. Enquanto os não residentes apresentam uma marca superior a 19.000 pedidos no mesmo período. Observando que são pedidos não específicos para área têxtil. Isso indica uma certa fragilidade da indústria têxtil brasileira quanto a sua vantagem competitiva na dimensão inovação. Ao mesmo tempo no que se refere a construção de marca quando se explicita, através das associações que representam essa indústria, que o design de jeanswear, homewear e moda praia são destaques no mercado internacional e efetivamente poderiam estar associados a uma marca reconhecidamente brasileira e protegida, não se verifica essa influência refletida em números relativos as exportações pelo reconhecimento de marcas brasileiras. Quanto as demais dimensões flexibilidade e alto padrão de qualidade são aqueles que têm ainda feito a diferença para manter a sua liderança no 
mercado interno. Observa-se na tabela 2 que os níveis de investimentos em máquinas, equipamentos e processos veem decaindo ao longo dos últimos anos. Isso pode ser caracterizado pela atualização da planta instalada em uma capacidade que satisfaz aos interesses dos investidores ou a falta de uma postura mais competitiva voltada para o mercado internacional. Devendo-se considerar que devido ao tamanho do mercado brasileiro exista uma certa acomodação decorrente da maior proximidade física e cultural.

Verifica-se também que não há indicação de promoção de marca para o mercado internacional se restringindo apenas a participação de feiras e rodadas de negócios promovidos pela ApexBrasil, que subsidia as indústrias a participarem desses eventos através de suas associações. Entendendo-se que existe uma fragilidade muito grande relativa a manutenção da sua liderança no mercado brasileiro, pois, só presença física nos pontos de vendas no atacado e pontos de vendas no varejo e ambientes informais de vendas diretas para atacado voltados para Micro e Pequenas Empresas (MPE) e Micro Empreendedor individual (MEI) e algumas poucas marcas e franquias com abrangência nacional, talvez não seja suficiente para assegurar essa liderança.

\section{Conclusões}

Com resultados obtidos observa-se a existência de baixa vantagem competitiva da indústria têxtil brasileira que é motivada pelo baixo nível de investimento em inovação tendo como resultado um participação ínfima no mercado mundial. Embora, que o mercado interno seja pouco agredido por importadores e entrada de empresas internacionais.

Observa-se, no entanto, que as importações encontram-se em uma crescente não podendo ser desprezada. Por outro lado, também é percebida a falta de inovações pelo baixo número de depósitos de patentes voltados para este setor. Daí recomenda-se estabelecer novas estratégias para desenvolver produtos e marcas de alto valor agregado com uma sistemática de alta produtividade que já foi alcançada. Dessa forma, mantendo-se os procedimentos atuais aumentará a possibilidade de perda interna de mercado aumentando o deficit na balança comercial para esse setor.

Ainda considerando os aspectos teóricos relativos aos ganhos de vantagem competitiva são identificadas as características das empresas que estão localizadas nos países que despontam como maiores exportadores. Essas características estão associadas a capacidade de inovar em processos e produtos, em desenvolvimento de máquinas e equipamentos e em técnicas de melhorias de insumos de fibras de algodão (principalmente cultivares de algodão) e fibras sintéticas.

No entanto, é observado que no que se refere ao desenvolvimento de marcas poucos países tratam esse atributo, não menos importantes que os demais. Nesse sentido aqueles países que 
desenvolvem marcas voltadas para a indústria da moda não chegam a ser os maiores exportadores exportando volumes significativos de produtos de alto valor agregado.

Dessa forma, pode-se entender que a melhor maneira de proteger o mercado interno é ter estratégias focadas nas tendências do mercado mundial observando quais são os principais concorrentes e os seus posicionamentos quanto inovação, construção e promoção de marcas, flexibilidade, produção com padrão de alta qualidade. Aspectos esses que não são desenvolvidos por ações individuais e sim, por políticas definidas para o setor através de associações e órgão de fomento. Caracterizando-se então, como uma estratégia de país.

\section{Referências}

Amparo, K. K., Ribeiro, M. D., \& Guarieiro, L. L. (2012). Estudo de caso utilizando mapeamento de prospecção tecnológica como principal ferramenta de busca científica. Perspectivas Em Ciência Da Informação, 17(4), 195-209. https://doi.org/10.1590/s1413-99362012000400012

Carlota, M. C. (2018). A Indústria 4.0 aplicada aos Setores da Moda (Dissertação de Doutorado).

Cassiolato, J. E., \& Lastres, H. M. (2000). Sistemas de inovação: Políticas e perspectivas. Parcerias Estratégicas.

Coelho, G. M., Santos, D. M. D., Santos, M. D. M., \& Fellows Filho, L. (2010). Caminhos para o desenvolvimento em prospeç̧ão tecnológica: Technology Roadmapping-um olhar sobre formatos e processos. Parcerias Estratégicas, 10(21), 199-234.

Cohen, S. S., \& Zysman, J. (1987). Manufacturing matters. New York: Basic Books.

Costa, A. C. R. D., \& Rocha, É. R. P. D. (2009). Panorama da cadeia produtiva têxtil e de confecções e a questão da inovação.

Coutinho, L., \& Ferraz, J. C. (1994). Estudo da competitividade da indústria brasileira. Campinas, SP: Papirus.

Donnelly et.al. (1992). Fundamentals of management. Homewood: Irwin, 840 p.

Dibrella, C., Craigb, J., B., Neubaumc, D., O., (2014). Linking the formal strategic planning process, planning flexibility, and innovativeness to firm performance. Volume 67, Issue 9, Pages 20002007. https://doi.org/10.1016/j.jbusres.2013.10.011

Dytrt, Z., Striteska, M., (2009). Efektivni inovace: odpovednost v managementu. Vyd. 1. Brno: Computer Press, 150 s. ISBN 978-80-251-2771-1.

FIEG. Relatório sobre o posicionamento da Industria Brasileira 2018. Goiana.

IEMI. Instituto de Estudos e Marketing Industrial Ltda. Brasil têxtil: relatório setorial da indústria têxtil brasileira 2017. São Paulo, IEMI, v.17, nr. 17, ago. 2018. 
Geldes, C., Felzensztein, C.,Palacios-Fenech, P. (2017) Technological and non-technological innovations, performance and propensity to innovate across industries: The case of an emerging economy. Industrial Marketing Management, V. 61, February, Pages 55-66. https://doi.org/10.1016/j.indmarman.2016.10.010

Haguenauer, L. (1989). Competitividade: conceitos e medidas: uma resenha da bibliografia recente com ênfase no caso brasileiro. Texto para discussão, 211.

Hakes, Ch. (2007). The EFQM Excellence Model. UK Zaltbommel, Van Haren Publishing, pp.1-15.

Kislingerova, E., (2008). Inovace nastroju ekonomiky a managementu organizaci. Vyd. 1. Praha: C. H. Beck, xxi, 293 s. ISBN 978-80-7179-882- 8.

Koubek, J., 2011. Personalni prace $v$ malych a strednich firmach: 4. evropske vydani. 4., aktualiz. a dopl. vyd. Praha: Grada, 281 s. Management (Grada). ISBN 978-80-247-3823-9.

Kožená, M. \& Chládek, T. (2012). Company competitive new mensurement depending on its size and find of activitis. Procedia - Social and Behavioral Sciences 58 (2012) 1085 - 1090

Kupfer, D. (1992). Padrões de concorrência e competitividade. Encontro Nacional da ANPEC, 20, 355372.

Kupfer, D., \& Hasenclever, L. (2013). Economia industrial: fundamentos teóricos e práticas no Brasil. Elsevier.

Kurian, George Thomas. (2013) The AMA dictionary of business and management. ISBN 13: 987-08144-2028-7. American Management Association.

Lau, A. K.W., (2015). Regional innovation system, absorptive capacity and innovation performance: An empirical study. In: Technological Forecasting and Social Change, Volume 92, Pages 99-114. https://doi.org/10.1016/j.techfore.2014.11.005

Lens.Org. https://www.lens.org/lens/search/patent/structured

Milnitz, D., Mendes Luna, M. M., \& Coelho, A. S. (2016). Cálculo e análise da capacidade produtiva utilizando o processo de Markov: estudo de caso de uma empresa têxtil. Exacta, 14(1).

O Poder da Moda [PDF]. (n.d.). São Paulo: ABIT. Recuperado em 30 de junho de 2020, em https://www.abit.org.br/adm/Arquivo/Publicacao/120429.pdf

Palomino, E. (2002). A moda. Publifolha.

Perfil do Setor. (2019). Recuperado em 30 de junho de 2020, em https://www.abit.org.br/cont/perfildo-setor

Porter, M. (2004). Estratégia competitiva. Elsevier Brasil.

Porter, M. E. (2004). Vantagem competitiva: Criando e sustentando um desempenho superior. Rio de Janeiro, RJ: Ed. Campus.

Possas, M. L. (1995). A cheia do "mainstream": comentário sobre os rumos da ciência econômica. Revista de Economia Contemporânea, 1(1). 
Possas, S. (1999). Concorrência e competitividade: Notas sobre estratégia e dinâmica seletiva na economia capitalista. São Paulo, SP: Ed. HUCITEC.

Prado, M. V. (2018). Relatório Setorial da Indústria Têxtil Brasileira. IEMI, 18(18), 192.

Raska, Z., (2007). Inovace ve financnim rizeni: 4. evropske vydani. 1. vyd. Praha: Alfa Publishing, 211 s. ISBN 978-80-86851-65-5.

Subramain, N., Gunasekaran, A., Yu, J., Cheng, J., Ning, K., (2014). Customer satisfaction and competitiveness in the Chinese E-retailing: Structural equation modeling (SEM) approach to identify the role of quality factors, In: Expert Systems with Applications, Volume 41, Issue 1, Pages 69-80. https://doi.org/10.1016/j.eswa.2013.07.012

The Lens https://www.lens.org/lens/

Tidd, J., Bessant, J., \& Pavitt, K. (2008). Gestão da inovação. Porto Alegre, RS: Bookman.

Veber, J., (2007). Rizeni jakosti a ochrana spotrebitele. Praha: Grada. ISBN 978-80-247-1782-1.

Watson, G., Gallagher, K. and Armstrong, M. (2005), Managing for Results. London, Chartered Institute of Personnel and Development, pp. 257- 259. 